\title{
Detection of a Real Time Remote Sensing Indices and Soil Moisture for Drought Monitoring and Assessment in Jordan
}

\author{
Ibrahim A. Farhan ${ }^{1 *}$, Jawad Al-Bakri² \\ ${ }^{1}$ The University of Jordan, School of Arts, Geography Department, Amman, Jordan \\ ${ }^{2}$ The University of Jordan, School of Agriculture, Land, Water and Environment Department, Amman, Jordan \\ Email: *Ibmfrhan@yahoo.com
}

How to cite this paper: Farhan, I.A. and Al-Bakri, J. (2019) Detection of a Real Time Remote Sensing Indices and Soil Moisture for Drought Monitoring and Assessment in Jordan. Open Journal of Geology, 9, 1048-1068. https://doi.org/10.4236/ojg.2019.913105

Received: September 30, 2019

Accepted: December 27, 2019

Published: December 30, 2019

Copyright (อ 2019 by author(s) and Scientific Research Publishing Inc. This work is licensed under the Creative Commons Attribution International License (CC BY 4.0).

http://creativecommons.org/licenses/by/4.0/

\section{(c) () Open Access}

\begin{abstract}
Drought monitoring represents a challenge for water and agricultural sector as this natural hazard accelerates water deficiency and leads to adverse environmental and socioeconomic impacts. The use of remote sensing data and geospatial techniques to monitor and map drought severity expanded in the last decades with progressive developments in data sources and processing. This study investigates the correlations among drought indices derived with soil moisture stress $(\mathrm{K})$ obtained from ground data collected from fields cultivated with barley. The study, carried out in Yarmouk basin in the north of Jordan, includes NDVI, PDI, MPDI and PVI derived from Landsat 8-OLI and Sentinel 2-MSI. Results showed different behavior among the indices and throughout the 2016/2017 growing season, with maximum correlation between PDI and MPDI followed by NDVI with PVI. Correlations among the remote sensing indices and $\mathrm{K}$ for different soil depths during March-April were significant for most indices with a maximum $\left(\mathrm{R}^{2}\right)$ of 0.82 for $\mathrm{K}_{30-50}$ and MPDI, followed by $\mathrm{K}_{30-50}$ with NDVI. Drought severity maps for the month of March showed different trends for the different indices, with similarities between MPDI and PDI. The map of drought severity combined from the remote sensing indices and $\mathrm{K}$ showed that PDI and soil moisture could significantly explain $56 \%$ of variations in spatial patterns of drought, while the combination of MPDI, PDI and NDVI could significantly explain up to 59\% of variations in drought severity map. Therefore, the study recommends the adoption of these remotely sensed indices for monitoring and mapping of agricultural droughts.
\end{abstract}

\section{Keywords}

Rainfed Crops, Soil Moisture, Drought Indices, Remote Sensing Data, 
Drought Map, Jordan

\section{Introduction}

Drought is a natural disaster that has many interrelated environmental and socioeconomic impacts related to the lack or shortage of water. With time, definitions of drought included four types that are: meteorological, agricultural, hydrological and socioeconomic [1]. The scientific consensus on drought defines this phenomenon as the condition of insufficient moisture caused by deficit precipitation over a period of time. Therefore, agricultural drought remains the most important type as the level of soil moisture content largely controls plant growth through the growing season. Since agricultural drought is highly correlated with soil moisture, monitoring of drought using soil moisture observations or indices related to soil moisture can provide important information for drought early warning systems.

Among many challenges that stand as obstacles for monitoring soil moisture conditions and drought severity during the different seasons is the good spatial distribution of instruments for measuring soil moisture and high cost of in-situ measurements for large geographical areas. The alternatives for the in-situ soil moisture measurements are the land surface models that integrate climatic and remote sensing data [2]. These coupled and uncoupled models for soil moisture estimation are limited by the level of accuracy which is highly limited by the input data for initial conditions and the coarse spatial resolution [3]. Alternatively, several techniques have revealed the ability of remote sensing data to extract indices that could indicate soil moisture and reflect drought conditions. The advantages of remote sensing techniques as potential tool for detecting for drought monitoring are their abilities to reveal the main three characteristics of drought which are intensity, duration and spatial coverage [4]. The techniques of remote sensing data are based on the assimilation of digital numbers (DNs), representing surface spectral reflectance at certain wavelength, to derive indices that are related to drought and reflecting soil moisture conditions. Most of these indices are derived from the red and near-infrared bands and assumed to reflect vegetation fractions and conditions.

During the last two decades, progressive developments in the geospatial techniques of remote sensing and geographic information systems (GIS) encouraged the use of remote sensing indices for monitoring drought and modeling its spatial patterns at different spatial and temporal scales [5].

The use of remote sensing data also increased due to its availability at reasonable or no cost. Good examples of these data are those of Landsat 8 and Sentinel-2, which are available free charge at spatial resolutions of 30 and 10 meters, respectively and temporal resolutions of 16 and 7 days, respectively. The most commonly used index that was derived from remote sensing and extensively 
used for monitoring vegetation condition is the Normalized Difference Vegetation Index (NDVI). The index shows good response to cumulative rainfall, except in arid areas or in environments with dense vegetation [6].

For drought monitoring, the concept of perpendicular drought index (PDI) was proposed to reflect moisture distribution in the red (R)-near-infrared (NIR) space [7]. The limitations of PDI are related to the assumptions of homogenous land cover and soil types. Therefore, a modified perpendicular drought index (MPDI) that considers vegetation fraction and soil moisture content was proposed for drought monitoring [8] The MPDI derived from the Landsat Enhanced Thematic Mapper Plus (ETM+) and the Moderate Resolution Imaging Spectroradiometer (MODIS) showed better performance than PDI in terms of drought monitoring [8].

In Jordan, adverse trends of climate changes and increased frequency and severity of droughts are expected to add more stresses to the countries scarce water resources [9] [10]. The country's water sector policy for drought management emphasized the need for a national drought early warning system to form the basis for decision-making and effective drought management planning [11]. This would require the adoption and use of credible indices that can detect drought and reflect soil moisture conditions, for the case of rainfed areas. At present, a unit for monitoring agricultural droughts is operating at the National Agricultural Research Center (NARC). The maps produced by this unit are based on the NDVI data of MODIS with spatial resolution of 1000. In these maps, severity of drought is based on the degree of NDVI deviation from the long-term means [12].

As a possible improvement in drought mapping, the drought monitoring unit at NARC started to use the $250 \mathrm{~m}$ resolution data of MODIS to produce maps of drought [13]. The maps were not assessed in terms of accuracy or correlation with soil moisture. For small geographical areas, the moderate resolution data of Landsat showed to be more accurate than MODIS data [14]. The use of either Landsat or MODIS data would depend on calibration and validation of indices using ground data.

The use of active remote sensing data of RADARSAT II to monitor soil moisture was also investigated in Jordan and showed accurate predictions [15]. However, several factors might restrict the use of such data sources including the low temporal resolution, the shallow soil depth represented by these data and the relatively high cost of moderate resolution data. Therefore, this study aims to assess different remotely sensed indices, derived from passive data, and their correlation with soil moisture for the purpose of agricultural drought monitoring in the north of Jordan. In addition, the study compares maps of drought generated from the different indices in terms of spatial distribution and rainfall gradient along the study area.

\section{Study Area}

The study was carried out in an area of $210 \mathrm{~km}^{2}$ inside the Yarmouk River Basin 
(YRB). The basin inside the Jordan's border has an area of $1147 \mathrm{~km}^{2}$ (Figure 1), and covers the areas of Ramtha and Irbid in the north, and Mafraq in the east. The study area inside YRB was selected to cover rainfed crop of barley across the rainfall gradient inside the basin. The study area was selected as the rainfed areas inside this basin are under the threat of drought and desertification [15] [16]. The mean annual rainfall in the basin ranges between $150 \mathrm{~mm}$ in the east to 400 $\mathrm{mm}$ in the west, while the selected area has an annual rainfall of $230-350 \mathrm{~mm}$. The study area has mean annual minimum and maximum temperatures of $12.3^{\circ} \mathrm{C}$ and $23.1^{\circ} \mathrm{C}$, respectively.

The annual potential evaporation at the basin's level ranges from 1500 to 2150 $\mathrm{mm} /$ year [16]. The study area is flat and forms part of Horan plains with an altitude range of $560-600 \mathrm{~m}$. Soils of the study area are deep in the west and shallow (depth $<70 \mathrm{~cm}$ ) in the east with moderate to high clay contents. Both of

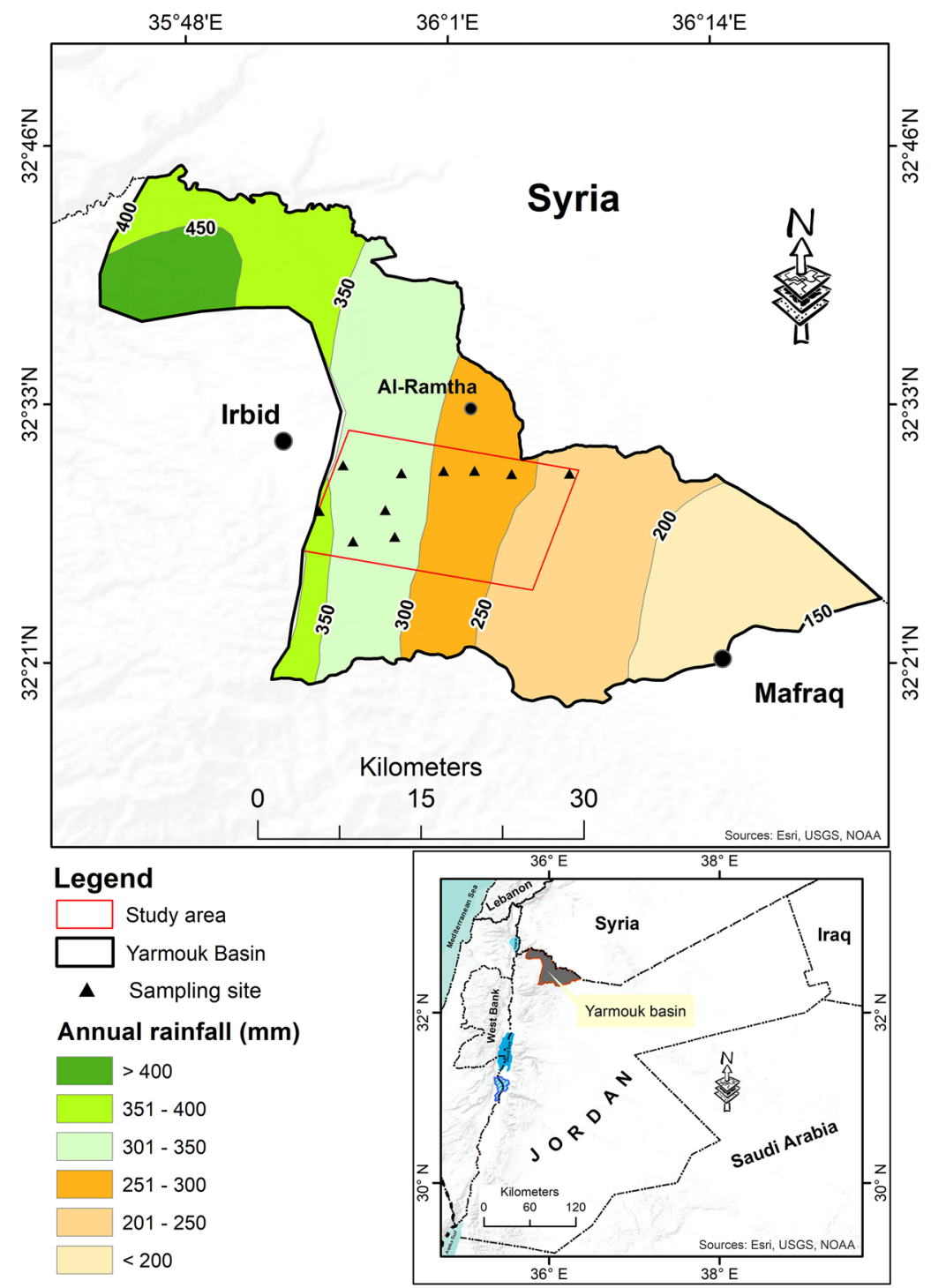

Figure 1. Location of the study area in the Yarmouk River Basin [11]. 
climate and land topography made the basin and the study area important agricultural areas where rainfed and irrigated agriculture are practiced. The main rainfed crops are field crops, olives and vegetables. The eastern part of the study area is cultivated with rainfed barley that is used to support grazing herds. The rainy season in this area starts in November and ends by early May, with most rainfall occurring in December-February.

Rainfall for $2016 / 2017$ season ranged between $107 \mathrm{~mm}$ in the east to $301 \mathrm{~mm}$ in the west. The season of barley cultivation starts by sowing in November-December and ends by harvesting in the Middle of May.

In the eastern parts of the basin and the study area, a transhumant system of cultivation is practiced where barley is usually cultivated for straw rather than for grain, to support the grazing herds of sheep, especially when drought is detrimental to grain yield.

\section{Methods}

The study methodology included a sequence of steps and procedures of data collection and analysis, as summarized in Figure 2. The data used in the study included satellite images of Landsat 8-Operational Land Imager (OLI), Sentinel 2-Multispectral Instrument (MSI) and climatic data from Jordan Meteorological Department (JMD) and Ministry of Water and Irrigation (MWI), in addition to ground data collected during several field visits. The following subsections include detailed description of these steps and procedures.

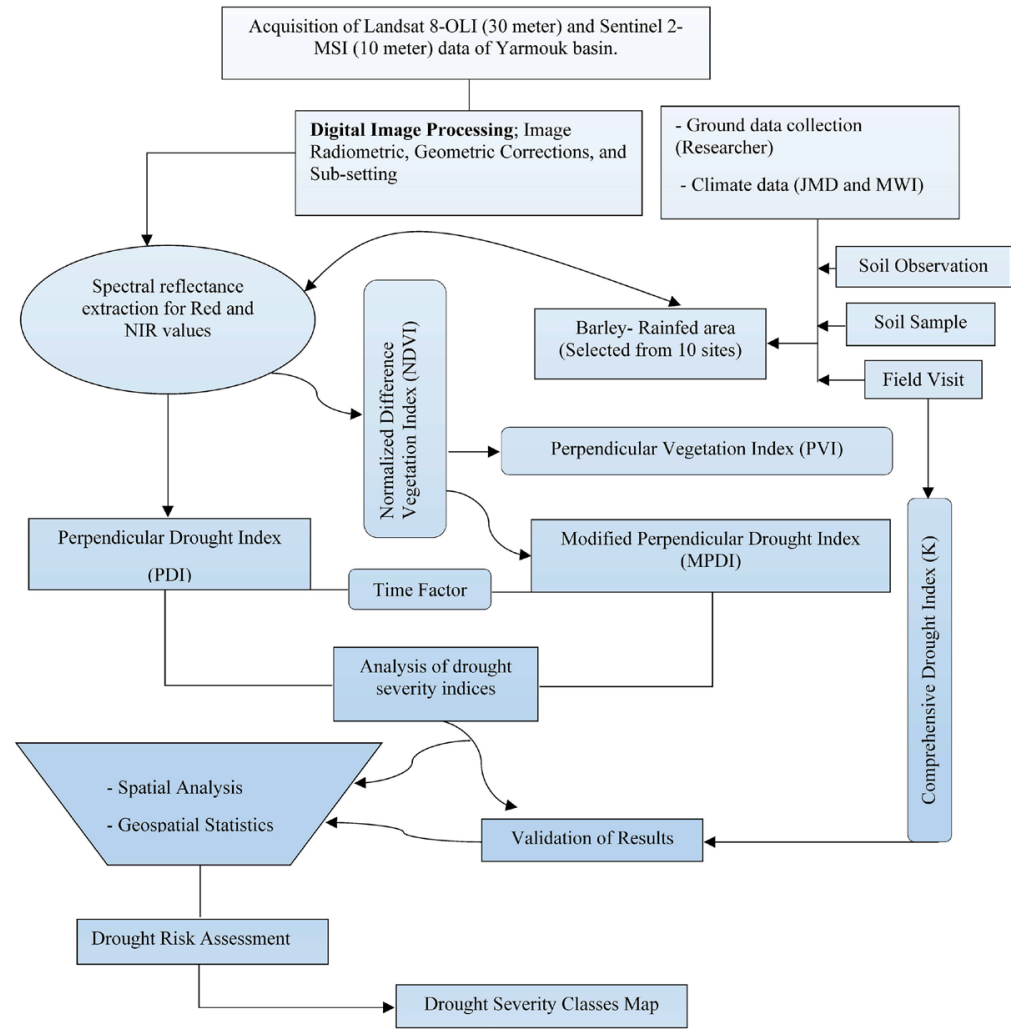

Figure 2. Flowchart of steps and methods for the study area. 


\subsection{Image Processing}

Landsat 8-OLI and Sentinel 2-MSI images for the 2016/2017 seasons were downloaded and processed to derive different drought indices that were correlated with soil moisture. The $30 \mathrm{~m}$ spatial resolution of the OLI data was considered as high resolution for drought mapping. However, due to cloud cover in some periods during the winter season, the MSI data with $10 \mathrm{~m}$ resolution was used for these periods. The two were characterized by having high correlated spectral data for atmospherically corrected images, i.e. data of spectral reflectance at ground level [17]. Since the study was based on multi-temporal images, atmospheric corrections were carried out using ground readings for reference objects collected by a hand held radiometer for one image and carrying out an image-to-image correction for the remaining images [10]. The images were also geometrically corrected using Ground Control Point's (GCP's) collected with a Global Positioning System (GPS) that had an accuracy of $\pm 3 \mathrm{~m}$. A second order transformation model was used to correct the images that were resampled to 30 $\mathrm{m}$ pixel size. The images included multispectral bands with different wavelengths. In this study, only the red and the NIR bands were used for deriving the indices used for drought monitoring. The data covered the period October 2016-May 2017, corresponding the 2016/2017 growing season (see Table 1).

\subsection{Derivation of Drought Indices}

The processed data of OLI and MSI was used to derive four indices selected for drought monitoring as summarized in the following points.

1) $N D V I$

This is the most commonly used index to monitor vegetation. The index was calculated by using red and NIR bands as follows [6]:

$$
N D V I=\frac{(N I R-R)}{(N I R+R)}
$$

where $N I R$ and $R$ are the reflectance of near-infrared red bands, respectively.

2) $P V I$

The perpendicular vegetation index $(P V I)$ is distinct; orthogonal to the soil line and can be used for computing the maximum signals of the green vegetation taking into account the effect of soil background. The index was calculated as follows [18]:

$$
P V I=\sqrt{\left(R_{s}-R_{v}\right)^{2}+\left(N I R_{s}-N I R_{v}\right)^{2}}
$$

where the subscripts $s$ and $v$ refer to the soil and vegetation reflectance, respectively. The soil line was generated by extracting the values of red and NIR bands for the study area to derive the slope and intercept. Locations of the sampled sites, in terms of red and NIR reflectance, were plotted on this cure to study the variations in vegetation cover among the sampled sites and to determine which of these sites would be highly affected by possible drought or soil moisture stress. 
Table 1. Specification remote sensing data used in the study.

\begin{tabular}{ccc}
\hline Source & $\begin{array}{c}\text { Band } \\
\text { (Nominal: wavelength, } \mu \mathrm{m})\end{array}$ & $\begin{array}{c}\text { Dates } \\
\text { (DD-MM-YY) }\end{array}$ \\
\hline & & $16-10-2016,20-01-2017$, \\
Landsat 8-OLI & 4 (Red: $0.636-0.673)$ & $05-02-2017,21-02-2017$, \\
& 5 (NIR: $0.851-0.879)$ & $26-04-2017,12-05-2017$, \\
& $28-05-2017$ \\
Sentinel 2-MSI & 4 (Red: $0.665-0.695)$ & $23-10-2016,12-11-2016$, \\
& 8 (NIR: $0.842-0.957)$ & $22-11-2016,22-12-2016$, \\
& & $11-01-2017,12-03-2017$ \\
\hline
\end{tabular}

3) $P D I$

This drought index was derived using spatial characteristics of the soil moisture in Red and NIR feature space to assess soil moisture stress. The equation to derive $P D I$ is [7] [19]:

$$
P D I=\frac{1}{\sqrt{M^{2}+1}}(R-(M \times N I R))
$$

where $M$ is the slope of the soil line in the Red-NIR spectral feature space. The value (1.30) was derived from using the linear relationship between $R$ and NIR [14].

4) $M P D I$

This index considers vegetation fraction and soil moisture content and does not assume uniform vegetation and soil types. Depending on the area under consideration, $M P D I$ may perform better than $P D I$. The Fraction of Vegetation $\left(f_{v}\right)$ was calculated, using the maximum and minimum $N D V$ values of the scene, according to the following equation [20]:

$$
f_{v}=1-\left(\frac{N D V I_{\max }-N D V I}{N D V I_{\max }-N D V I_{\min }}\right)^{0.6175} .
$$

The range of $f_{v}$ is 0 (bare soil) to 1 (full vegetation cover). After deriving the $f_{V}$ layer, the MPDI was calculated as follows [8]:

$$
M P D I=\frac{R+\left(M \times N I R-f_{v}\left(R_{v}+M \times N I R_{v}\right)\right)}{\left(1-f_{v}\right) \sqrt{M^{2}+1}} .
$$

\subsection{Ground Data Collection}

Soil moisture samples were collected from ten sites (fields) in the study area during the 2016/2017 season. The sites were selected to represent an east-west transect that covers the rainfall gradient in the study area, with a distance of 3 - 4 $\mathrm{km}$ between the field and the other (Figure 3). Also, the selection included the fields that were planted on the same data (10th of December 2016). These included eight rainfed fields cultivated with barley, one field cultivated with barley under supplemental irrigation and one bare field that included natural grasses used for grazing. The sites were characterized by flat topography and fine to medium soil texture that had high water holding capacity. 


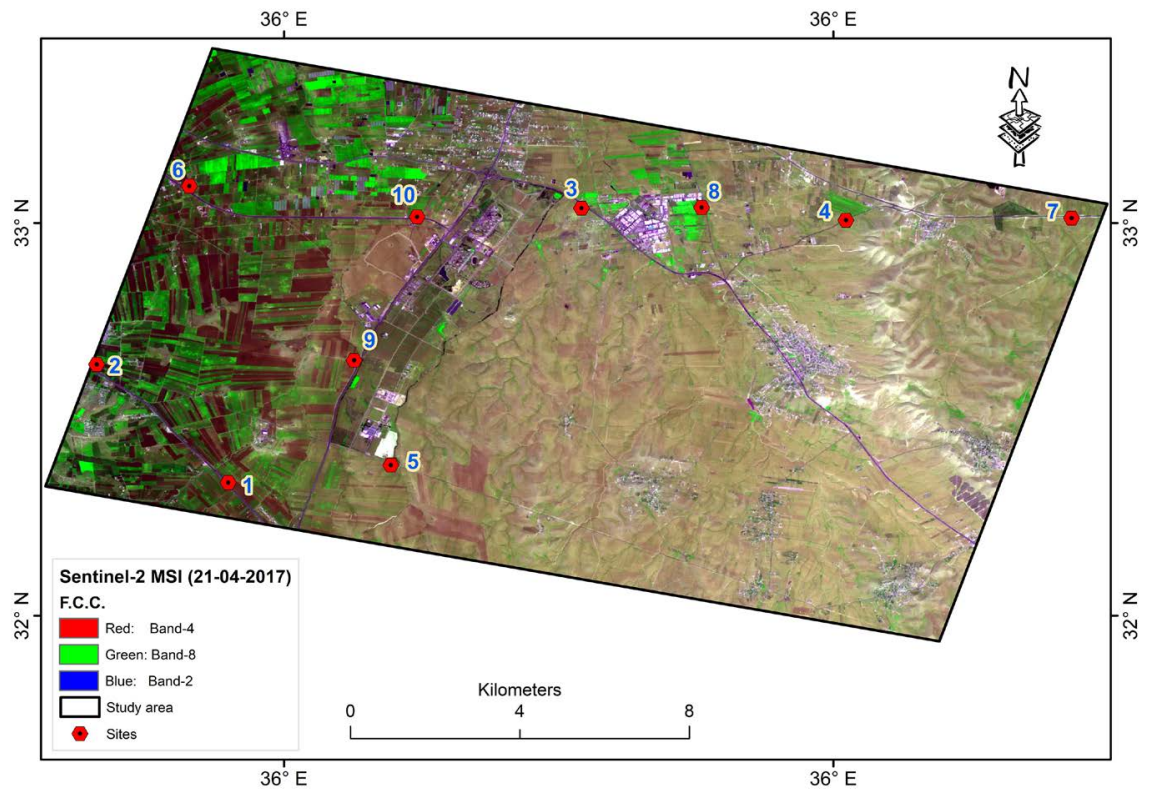

Figure 3. Distribution of sampling sites over the study area overlaid onto MSI image.

The variations in soil content of clay were obvious where maximum contents of clay were in the high rainfall area in the west. A summary of some soil physical properties of the selected sites are shown in Table 2. In addition to soil sampling, measurements were made for plant heights inside the 10 sites using a diagonal transect inside each site during January-May. Gravimetric soil samples were collected in the days coincided with the satellite overpass. Samples were taken by an auger from three depths extending from surface down to $50 \mathrm{~cm}(0-$ 10, 10 - 30 and 30 - 50). Physical characterization for particle size distribution, bulk density and volumetric water contents at field capacity and permanent wilting point was also carried out for the collected samples.

The volumetric soil moisture content $\left(\theta_{v}\right)$ was measured for each soil sample and the equivalent soil moisture content $(W)$ was then calculated for each depth and for each sampling site. Soil moisture stress $(K)$ was calculated using the following equation [21]:

$$
K=1-\frac{W-W_{p}}{W_{h}-W_{p}}
$$

where, $W$ is the equivalent soil moisture content for a particular soil depth or layer, $W_{h}$ and $W_{p}$ are the Field Capacity (FC) and Permeant Wilting Points $(P W P)$, respectively, for that soil depth or layer. When the value of $\mathrm{K}$ approaches zero then plant will not suffer from water stress, while values closer to one indicate conditions of water stress resulting from low levels of soil moisture.

\subsection{Drought Severity Mapping}

A map of drought severity was produced for the month of March using the maps of drought level based on PDI, MPDI, PVI and K maps and using the ranges 
Table 2. Summary of some soil physical properties of the sampling sites in the study area.

\begin{tabular}{|c|c|c|c|c|c|c|c|}
\hline Site & $\begin{array}{c}\text { Harvesting } \\
\text { (DD-MM-YY) }\end{array}$ & $\begin{array}{l}\text { Clay } \\
(\%)\end{array}$ & $\begin{array}{l}\text { Silt } \\
(\%)\end{array}$ & Sand (\%) & Soil Texture & $\begin{array}{c}\mathrm{FC} \\
(\mathrm{cm} / \mathrm{cm})\end{array}$ & $\begin{array}{c}\text { PWP } \\
(\mathrm{cm} / \mathrm{cm})\end{array}$ \\
\hline 1 & 28-05-2017 & 52.3 & 42.2 & 5.5 & Silty clay & 0.39 & 0.25 \\
\hline 2 & N/A & 57.3 & 38.4 & 4.3 & Clay & 0.45 & 0.32 \\
\hline 3 & $28-05-2017$ & 39.6 & 52.9 & 7.5 & Silty clay loam & 0.30 & 0.17 \\
\hline 4 & $12-05-2017$ & 18.9 & 65.9 & 15.2 & Silt loam & 0.32 & 0.19 \\
\hline 5 & $28-05-2017$ & 41.5 & 51.7 & 6.8 & Silty clay & 0.37 & 0.22 \\
\hline 6 & $28-05-2017$ & 34.8 & 55.5 & 9.7 & Silty clay loam & 0.40 & 0.20 \\
\hline 7 & $10-04-2017$ & 33.1 & 54.8 & 12.1 & Silty clay loam & 0.36 & 0.18 \\
\hline 8 & $28-05-2017$ & 30.2 & 60.8 & 9.0 & Silty clay loam & 0.43 & 0.20 \\
\hline 9 & $28-05-2017$ & 28.4 & 60.3 & 11.3 & Silty clay loam & 0.35 & 0.20 \\
\hline 10 & $28-05-2017$ & 33.1 & 56.8 & 10.1 & Silty clay loam & 0.34 & 0.19 \\
\hline Site & $\begin{array}{c}\text { Harvesting } \\
\text { (DD-MM-YY) }\end{array}$ & $\begin{array}{l}\text { Clay } \\
(\%)\end{array}$ & $\begin{array}{l}\text { Silt } \\
(\%)\end{array}$ & Sand (\%) & Soil Texture & $\begin{array}{c}\mathrm{FC} \\
(\mathrm{cm} / \mathrm{cm})\end{array}$ & $\begin{array}{c}\text { PWP } \\
(\mathrm{cm} / \mathrm{cm})\end{array}$ \\
\hline 1 & 28-05-2017 & 52.3 & 42.2 & 5.5 & Silty clay & 0.39 & 0.25 \\
\hline 2 & N/A & 57.3 & 38.4 & 4.3 & Clay & 0.45 & 0.32 \\
\hline 3 & $28-05-2017$ & 39.6 & 52.9 & 7.5 & Silty clay loam & 0.30 & 0.17 \\
\hline 4 & $12-05-2017$ & 18.9 & 65.9 & 15.2 & Silt loam & 0.32 & 0.19 \\
\hline 5 & 28-05-2017 & 41.5 & 51.7 & 6.8 & Silty clay & 0.37 & 0.22 \\
\hline 6 & 28-05-2017 & 34.8 & 55.5 & 9.7 & Silty clay loam & 0.40 & 0.20 \\
\hline 7 & 10-04-2017 & 33.1 & 54.8 & 12.1 & Silty clay loam & 0.36 & 0.18 \\
\hline 8 & 28-05-2017 & 30.2 & 60.8 & 9.0 & Silty clay loam & 0.43 & 0.20 \\
\hline 9 & $28-05-2017$ & 28.4 & 60.3 & 11.3 & Silty clay loam & 0.35 & 0.20 \\
\hline 10 & $28-05-2017$ & 33.1 & 56.8 & 10.1 & Silty clay loam & 0.34 & 0.19 \\
\hline
\end{tabular}

shown in Table 3. The NDVI was excluded as drought classification using this index would require the use of long historical record and the use of seasonal deviations from the long term mean assuming normal distribution of data [12]. The indices used for drought mapping, on the other hand, did not require the assumption of normal distribution and the map of drought could be carried out for a single image [21]. The month of March was selected as growth of rainfed crops would reach its peak during this month [12] [14].

\subsection{Evaluation of Results}

The derived remote sensing indices were assessed in terms of correlation with soil moisture stress for the different soil layers and for the root zone. A correlation matrix was used to analyze the extent of interdependence between different drought indices. In addition, other statistical parameters of minimum, maximum, mean, standard deviation, Root Mean Square Error (RMSE) were also derived and summarized for the derived indices (Table 4). The data of vegetation indices was also plotted for the sampling sites during the growing season using 
Table 3. Classification of drought severity for the different vegetation and soil moisture indices.

\begin{tabular}{ccccc}
\hline \multirow{2}{*}{ Class } & \multicolumn{4}{c}{ Indicator and range } \\
\cline { 2 - 4 } & MPDI & PDI & PVI & K \\
\hline No Drought & $0-0.3$ & $0-0.3$ & $>18$ & - \\
Mild & - & - & $15-18$ & $0.2-0.4$ \\
Moderate & $0.3-0.5$ & $0.3-0.5$ & $12-15$ & $0.4-0.6$ \\
Severe & $0.5-0.8$ & $0.5-0.8$ & $9-12$ & $0.6-0.8$ \\
Extreme & $0.8-1.0$ & $0.8-1.0$ & $<9$ & $0.8-1.0$ \\
\hline
\end{tabular}

Table 4. A statistical summary of the vegetation indices and $\mathrm{K}$ in the sampling sites.

\begin{tabular}{cccccc}
\hline Index & Minimum & Maximum & Mean & Standard deviation & RMSE \\
\hline PVI & 0.1 & 21.8 & 4.9 & 0.042 & 0.017 \\
NDVI & 0.044 & 0.853 & 0.216 & 0.160 & 0.035 \\
MPDI & 0.05 & 0.54 & 0.30 & 0.104 & 0.064 \\
PDI & 0.13 & 0.52 & 0.31 & 0.087 & 0.055 \\
K & 0.058 & 0.948 & 0.440 & 0.205 & 0.133 \\
\hline
\end{tabular}

the red and NIR reflectance data. This was carried out to assess the different indices in terms of their ability to detect vegetation conditions inside the sampled sites and their locations in the spectral space in relation to soil line during wet and dry periods [8]. Also, the plot would reflect the levels of soil moisture during the growing season.

The map of drought was assessed in terms of its correlation with maps of remote sensing indices and rainfall. This was carried out using the exploratory regression analysis within the GIS environment. The exploratory regression evaluates all possible combinations of the input candidate explanatory variables, looking for Ordinary Least Squares (OLS) models that best explain the dependent variable. The exploratory or independent variables included the NDVI, PVI, PDI, MPDI, rainfall and K for different soil depths, while the dependent variable included the map of drought. The results from OLS and exploratory regression also included the assessment of model significance (using Joint $\mathrm{F}$ and Wald Statistics), redundancy of variables (indicated by variance inflation factor, VIF), and the normality of the model residuals for each variable using Jarque-Bera (JB) statistics, which indicates normal distribution of variable when JB is zero [22] [23].

\section{Results and Discussions}

\subsection{Assessment of Vegetation and Drought Indices in the Sampled Sites}

Results showed variation in the level of vegetation cover in the study area, where 
the reflectance of the vegetation was orthogonal to the soil line and the value of reflectance for the sites with vegetation was more than $27 \%$ in the NIR band and less than $10 \%$ in the red band (Figure 4). Among the sampled locations, site 8 had the full vegetation cover, while variations in the level of vegetation and the value of vegetation indices were observed. Generally, the sites showed variations in vegetation cover and the values of vegetation soil moisture stress throughout the growing season (Table 5).

The maximum values of PVI were observed in the MSI image of the 12th of March with higher values for sites of 1, 6, 8 and 10 than other sites (Figure 4). Similarly, the maximum values of NDVI were observed during the same period. Both of PVI and NDVI agreed with the field observations and measurements collected for Plant Height (PH) inside the sampling sites (see Table 5). As such, significant correlations $(p<0.05)$ between plant height and PVI and NDVI were observed in the sites cultivated with barley, where the coefficient of determination $\left(\mathrm{R}^{2}\right)$ was 0.51 for PH-PVI and 0.85 for PH-NDVI relationships.

The relatively low value of $\mathrm{R}^{2}$ for the case of PVI was attributed to its high sensitivity to the soil brightness [24]. Data from both OLI and MSI detected the variations in soil moisture for bare soils throughout the growing season (Figure 4). This was reflected on the spectral space of the red-NIR that showed high reflectance for dry soils than wet soils due to absorbance of electromagnetic radiation in the red and NIR wavelength. Among the examined indices, PDI was able to detect these variations during the growing season especially when soil was bare.

Plotting the data of PDI for dry and wet periods for both bare and vegetated soils, respectively, showed that PDI was parallel to the soil line and responded to soil moisture levels during the season (Figure 5). The line $\mathrm{L}$, which dissected the coordinate origin and is vertical to the soil line, delineated in Figure 5 and formulated from the soil line expression [7] would form the basis for the PDI concept.

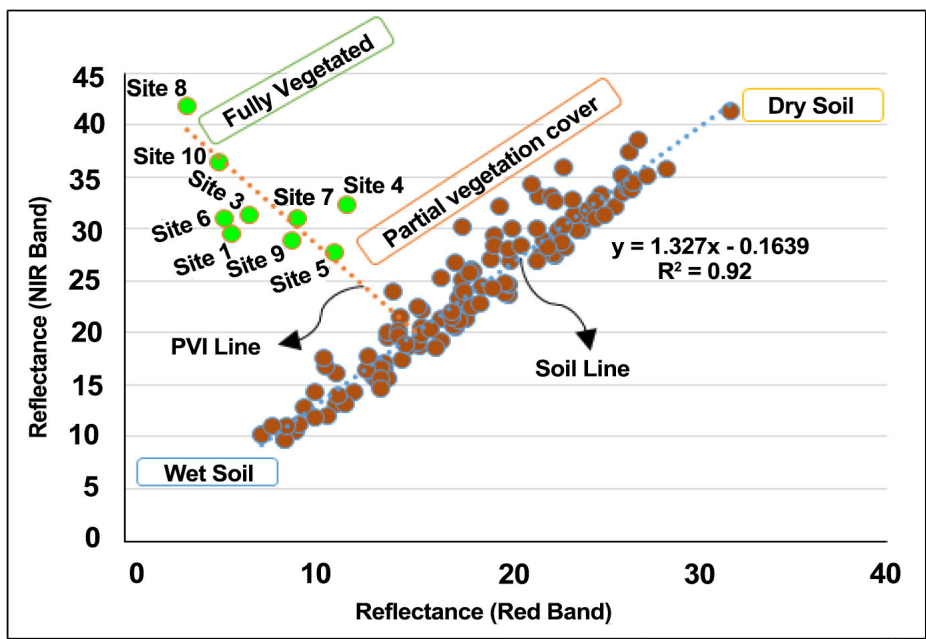

Figure 4. Spectral space of red-NIR bands during the growing season and PVI for sampled sites during March. 


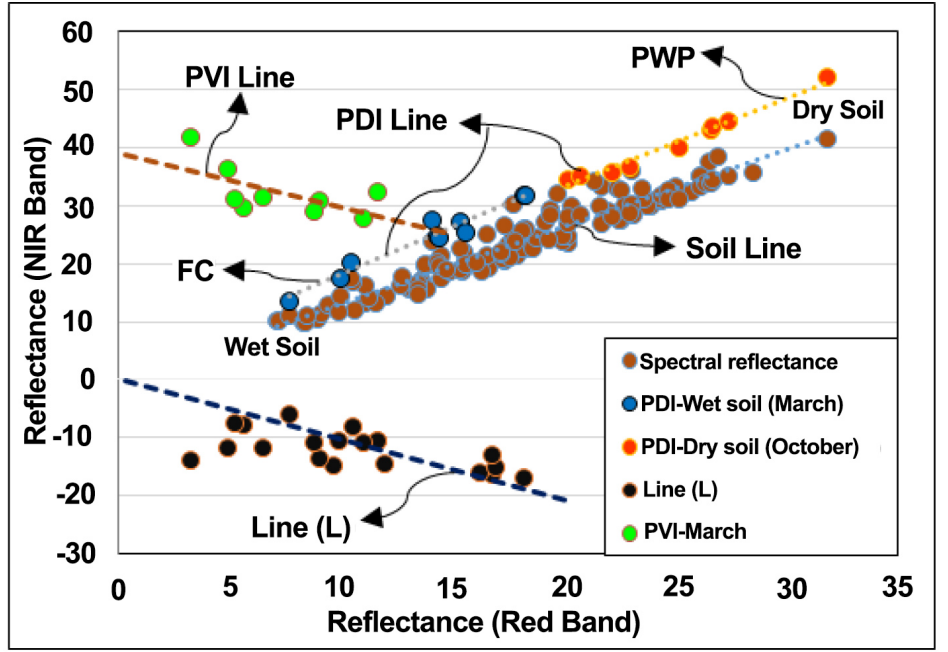

Figure 5. Spectral space of red-NIR bands and PDI during the growing season, PVI during March and PDI for the wet and the dry periods.

Table 5. Mean values of measured plant height $(\mathrm{cm})$ and drought indices for the sampling sites.

\begin{tabular}{|c|c|c|c|c|c|c|c|c|c|c|}
\hline \multirow{2}{*}{ Site } & \multicolumn{10}{|c|}{ Date (DD-MM) } \\
\hline & 22-Dec. & 04-Jan. & 07-Feb. & 22-Feb. & 09-Mar. & 25-Mar. & 10-Apr. & 26-Apr. & 12-May & 28-Мау \\
\hline 1 & 0 & 9 & 16.5 & 18 & 26.5 & 50.1 & 67.5 & 70.2 & 57.5 & $\mathrm{H}$ \\
\hline 2 & 0 & 0 & 6 & 9 & 0 & 8 & 0 & 0 & 0 & 0 \\
\hline 3 & 0 & 7 & 9 & 14 & 19.1 & 31.5 & 35 & 40.1 & 37.5 & G \\
\hline 4 & 0 & 6 & 7.5 & 11.5 & 13 & 26.5 & 30 & 35.1 & G & G \\
\hline 5 & 0 & 0 & 7.5 & 7 & 10.1 & 13.9 & 30 & 37 & 37.5 & G \\
\hline 6 & 0 & 6.8 & 9.8 & 24 & 25.1 & 50.1 & 62.5 & 69.1 & 70 & $\mathrm{H}$ \\
\hline 7 & 0 & 4.5 & 8 & 13 & 22.1 & 24.9 & G & G & G & G \\
\hline 8 & 0 & 8.5 & 21 & 24 & 47.5 & 89.8 & 120 & 130 & 120 & $\mathrm{H}$ \\
\hline 9 & 0 & 4.5 & 8.5 & 10 & 20 & 29.1 & 37.5 & 49.6 & 50.1 & $\mathrm{H}$ \\
\hline 10 & 0 & 7 & 11 & 16 & 24.9 & 50 & 57.5 & 59.5 & 60.2 & $\mathrm{H}$ \\
\hline $\mathrm{CR}(\mathrm{mm})$ & 140 & 174 & 246 & 275 & 291 & 298 & 298 & 301 & 301 & 301 \\
\hline \multicolumn{11}{|l|}{ Index } \\
\hline NDVI & 0.08 & 0.20 & 0.22 & 0.28 & 0.38 & 0.55 & 0.20 & 0.18 & 0.20 & 0.22 \\
\hline PVI & 0.92 & 4.91 & 5.01 & 5.82 & 7.12 & 12.1 & 4.24 & 6.62 & 6.83 & 4.94 \\
\hline PDI & 0.20 & 0.22 & 0.18 & 0.23 & 0.26 & 0.31 & 0.29 & 0.23 & 0.37 & 0.35 \\
\hline MPDI & 0.20 & 0.18 & 0.23 & 0.25 & 0.32 & 0.28 & 0.16 & 0.36 & 0.31 & 0.34 \\
\hline $\mathrm{K}$ & 0.48 & 0.15 & 0.27 & 0.20 & 0.34 & 0.65 & 0.61 & 0.15 & 0.27 & 0.20 \\
\hline
\end{tabular}

Depth GG: Grazing; H: Harvest; CR: Cumulative Rainfall (mm).

For bare soil, the distance from any points in the NIR-Red spectral space to the line $\mathrm{L}$ represents the drought severity of the non-vegetated surface. The values of PDI when soil was dry (October) were located far away from this line, 
while PDI values when soil was wet (March) were closer to this line. The distance from PVI line to the line (L) was nearly the same for all sampling locations, indicating the low sensitivity of this index to soil moisture, although soil moisture levels were different among these sites.

Results showed significant correlations among some indices and no correlations among others (Table 6). The correlation coefficient reflected the nature of the remotely sensed indices which could be grouped into two groups that included PVI and NDVI in one group and PDI and MPDI in another group. The PVI and NDVI indices were mainly reflecting seasonal vegetation condition and showed higher correlations with the seasonal soil moisture stress. Previous work in Jordan [6] showed that NDVI was highly correlated cumulative rainfall rather than monthly or single rainfall event. The PDI and MPDI, on the other hand, were highly correlated and showed positive correlation with soil moisture. Both indices were low in January and February, indicating drought during this period when most rainfall occurred. This trend was not detected by PVI which indicated severe drought conditions during January and February and in other periods, except in March.

In general, PDI and MPDI reflected the conditions of drought in the study area with better response to rainfall than PVI. The values of NDVI, on the other hand, that maximum vegetation growth occurred during March and early April (at most), as indicated by the NDVI profile plotted for the sampled site (Figure 6). Since most of rainfall occurred during December-March, then this period could be considered as the critical period for monitoring drought in this Mediterranean environment. These results were also reported by previous research in Jordan [12] [13] [14] [25] which indicated that peak vegetation growth is reached by the end of March.

\subsection{Correlation among Indices and Soil Moisture}

Results showed variations in the degree of correlation between remotely sensed drought indices and soil moisture stress $(\mathrm{K})$ during the growing season and for short-term drought conditions (Table 7). For the period January-April, the relationship between remote sensing indices and $\mathrm{K}$ was insignificant for NDVI, while low values of $\mathrm{R}^{2}$ were observed for the relationships between other indices

Table 6. Correlation coefficient ( $r$ ) among indices for the 2016/2017 season.

\begin{tabular}{cccccc}
\hline Index & PVI & NDVI & MPDI & PDI & K \\
\hline PVI & 1.00 & 0.75 & $n^{*}$ & $n s$ & -0.44 \\
NDVI & 0.75 & 1.00 & ns & 0.24 & -0.50 \\
MPDI & ns & ns & 1.00 & 0.95 & 0.32 \\
PDI & ns & 0.24 & 0.95 & 1.00 & 0.30 \\
K & -0.44 & -0.50 & 0.32 & 0.30 & 1.00
\end{tabular}

*: No significant correlations at $p<0.05$. 
Table 7. Coefficient of determination $\left(R^{2}\right)$ for relationships between $\mathrm{K}$ and drought indices during January April (J-A) and March-April (M-A).

\begin{tabular}{ccccccccc}
\hline Index & \multicolumn{2}{c}{ NDVI } & \multicolumn{2}{c}{ PVI } & \multicolumn{2}{c}{ MPDI } & \multicolumn{2}{c}{ PDI } \\
\hline $\mathrm{K}_{\text {depth (cm) }}$ & J-A & M-A & J-A & M-A & J-A & M-A & J-A & M-A \\
\hline $\mathrm{K}_{0-10}$ & ns & 0.40 & ns & 0.27 & ns & 0.45 & ns & 0.34 \\
$\mathrm{~K}_{10-30}$ & ns & 0.70 & 0.18 & 0.61 & ns & 0.72 & 0.22 & 0.61 \\
$\mathrm{~K}_{30-50}$ & ns & 0.78 & 0.24 & 0.78 & 0.30 & 0.82 & 0.38 & 0.57 \\
$\mathrm{~K}_{0-50}$ & $\mathrm{~ns}$ & 0.68 & 0.19 & 0.56 & 0.16 & 0.72 & 0.26 & 0.55 \\
\hline
\end{tabular}

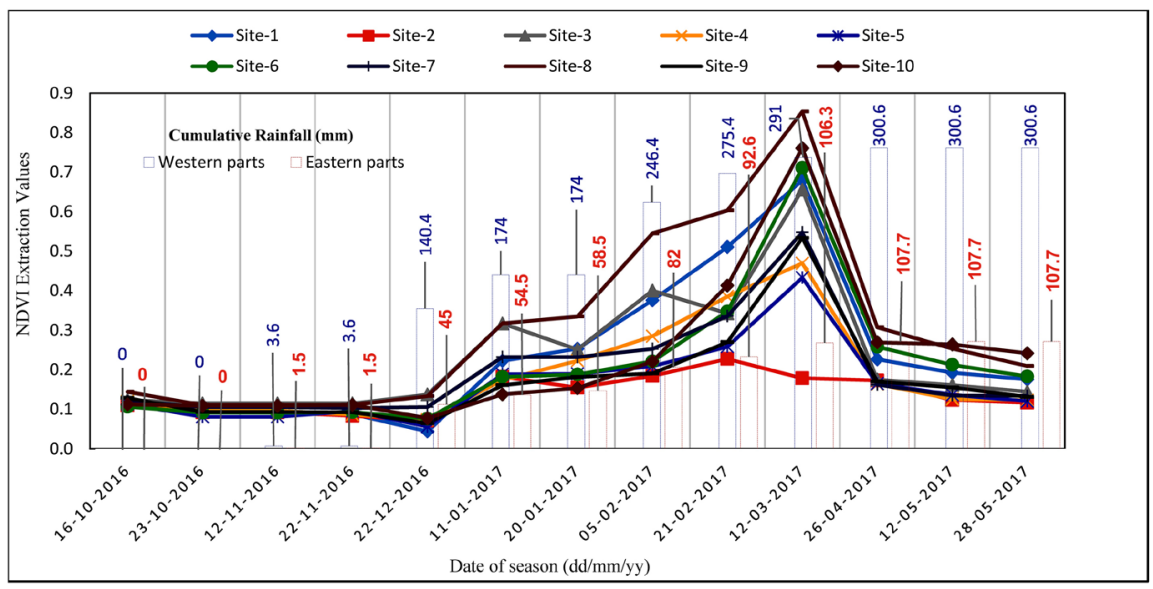

Figure 6. Spatiotemporal pattern of NDVI values and cumulative rainfall for each site during the season of 2016/2017.

and K. For the period March-April, significant relationships were observed among drought indices and $\mathrm{K}$ for the different soil depths. The maximum correlations occurred between MPDI and $\mathrm{K}$ for soil depths between 10 and $50 \mathrm{~cm}$. Generally, MPDI showed better correlations with soil moisture stress when compared with PDI. High correlations between MPDI and subsurface soil moisture was also indicated by Ghulam et al. [8] who proposed MPDI for real time drought monitoring.

The significant correlations with relatively high $R^{2}$ between NDVI, PVI and $\mathrm{K}$ could be explained by the fact that vegetation growth reached its peak during March and early April when soil moisture was depleted by plants. In this particular period, strong correlations were observed for subsurface soil moisture and remote sensing indices. The strong correlation between NDVI and soil moisture during March-April would also indicate the response of NDVI to cumulative rainfall during the season, as confirmed by previous research [6]. The relationships between drought indices and $\mathrm{K}$ were linear with PDI and MPDI being proportionally correlated with K, and NDVI and PVI being inversely correlated with $\mathrm{K}$. An example on these relationships is shown in Figure 7 for MPDI and NDVI during March-April.

The inverse relationships between NDVI and K might be confusing when used for drought monitoring as it would reflect the condition of plant reached at 

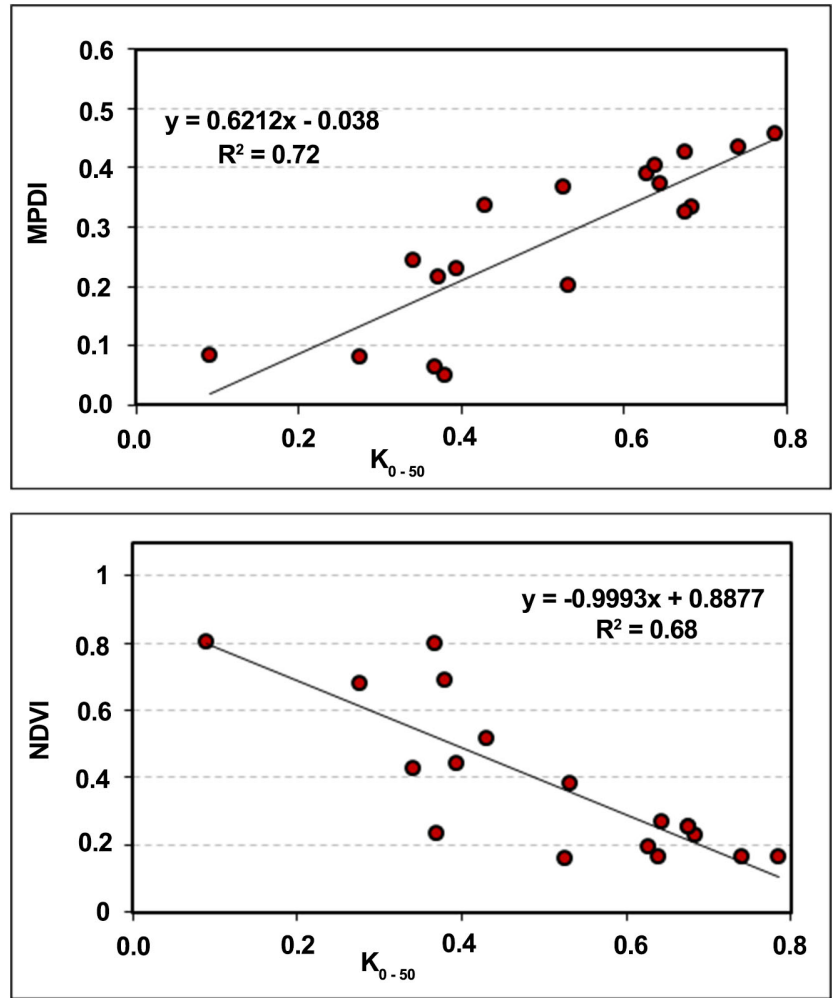

Figure 7. Relationships between $\mathrm{K}$ for the $0-50 \mathrm{~cm}$ soil depth and MDPI (top) and NDVI (bottom) during March-April.

this stage without reflecting drought severity. Also, the NDVI is well known for its sensitivity to soil background, soil wetness and saturation in its values for areas with dense vegetation [6] [26]. Therefore, MPDI would be recommended for drought monitoring during the periods of soil moisture stress in March and April as its values would reflect the severity of drought in relation to plant conditions. In terms of $R^{2}$, results were close to the values obtained by a previous study that correlated MPDI and PDI with soil moisture [14].

The results and relationships obtained from this study, however, would be more advantageous when compared with correlations made directly with soil moisture as the level of moisture stress would differ among the different soil types at the same soil moisture levels. Although both of PDI and MPDI would show similar spatial patterns (Figure 8), however, MPDI may perform better at stages of dense vegetation cover [27], like site 10 which had denser cover than other rainfed sites. In general, MPDI would reflect drought severity in relation to soil moisture stress regardless of soil type. Since the values of $R^{2}$ were slightly higher for K-MPDI relationship than for K-PDI relationship, the use of MPDI to monitor drought would be recommended.

\subsection{Drought Severity Mapping}

Maps of drought severity based on PDI, MPDI, PVI and K for March (see Figure 9) showed variations in spatial patterns of drought among the indices. Both 

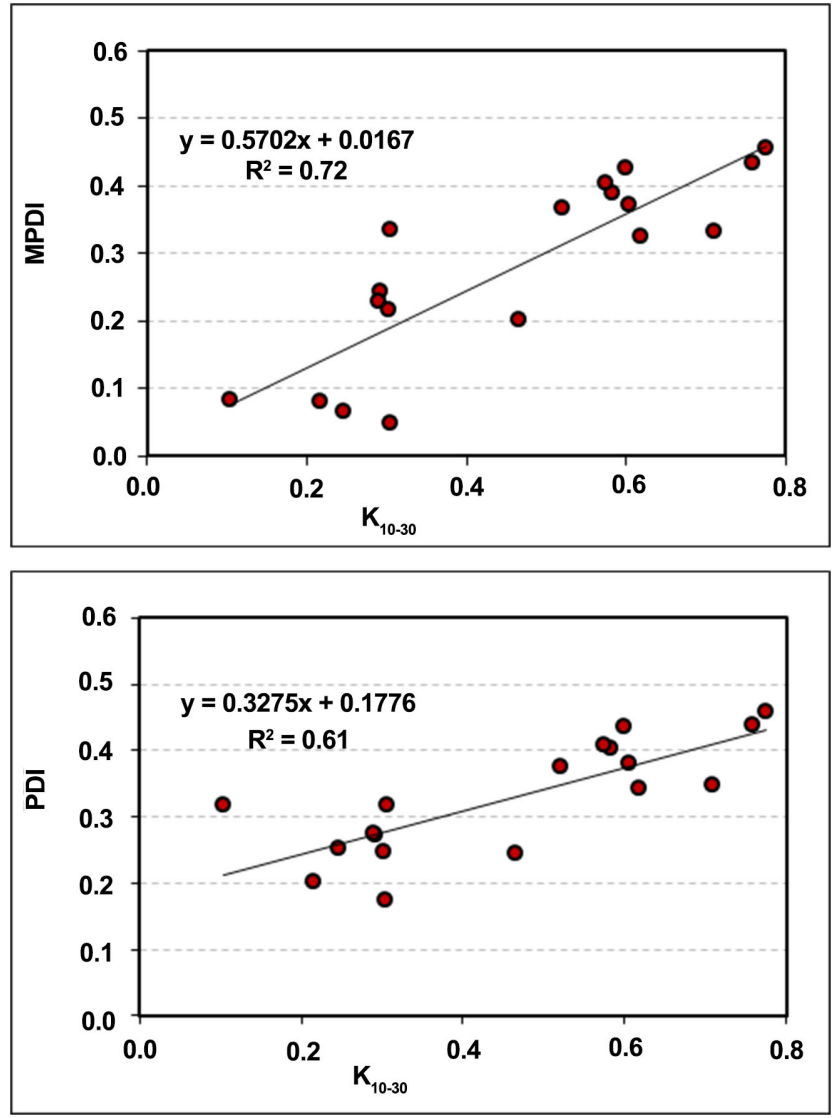

Figure 8. Relationships between the MDPI (top) and NDVI (bottom) and $\mathrm{K}$ for the $10-30 \mathrm{~cm}$ soil depth during March-April.

of MPDI and PDI had similar spatial pattern of drought in the western parts of the study area, while PDI showed larger areas in the middle and eastern parts affected by drought when compared with MPDI.

The map of PVI, on the other hand, reflected the variations in vegetation cover from the high rainfall zone in the west to the low rainfall zone in the east. The soil moisture stress showed different patterns than other indices particularly in the eastern parts of the study area and indicated mild to moderate moisture stress in March. The map of drought severity in March, combined the factors of vegetation and soil moisture across the study area (Figure 10). The map showed that half of the study area was exposed to moderate and severe drought while the eastern parts were suffering from extreme drought.

The map agreed with field observations collected during the growing season (Table 5), which showed that rainfed field crops in sites 1, 6, 9 and 10 had reached the ripening stage, while the crops in sites 3, 4, 5 and 7 reached harvest stage or were opened for grazing in early April. The areas with extreme drought in the east reflected the end of barley season in early April in these parts of the study area. Analysis of the factors that could explain the map of drought severity is shown in Table 8. The negative and positive signs in this table show the type of relationship between the independent variable and the drought severity map. 


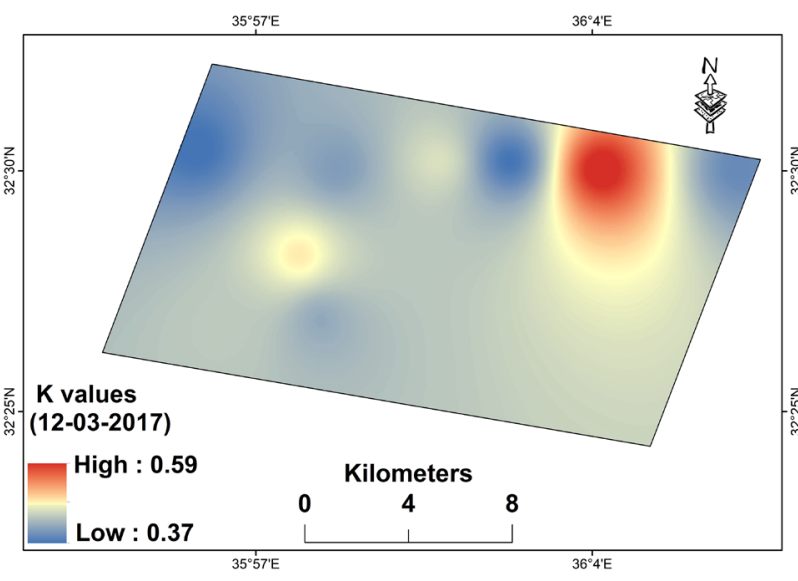

(a)

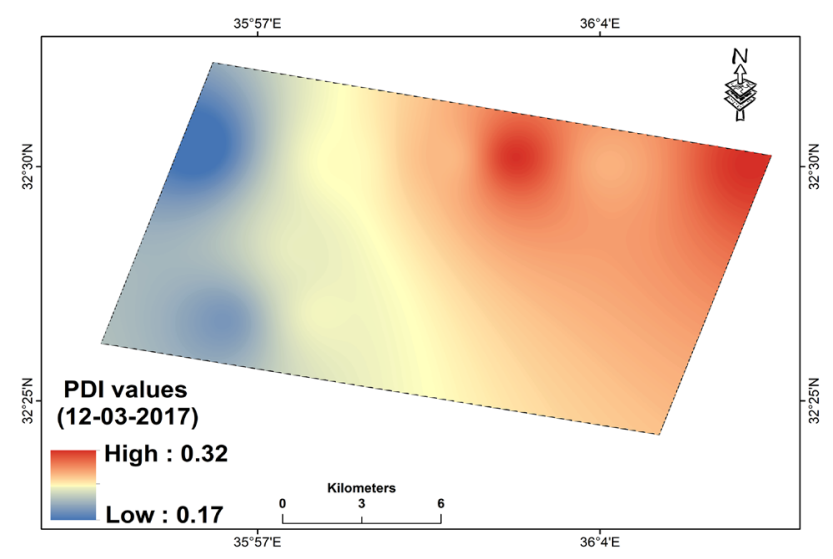

(c)

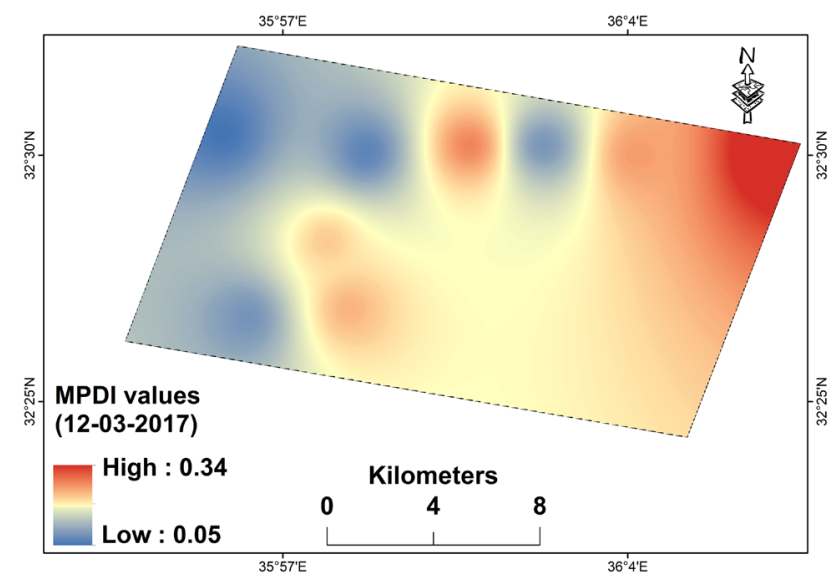

(b)

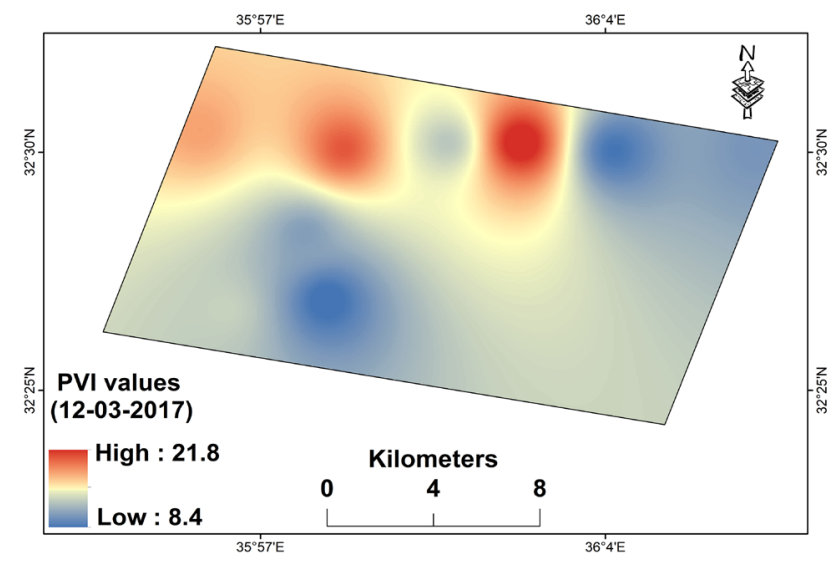

(d)

Figure 9. Maps of drought indices during March-2017.

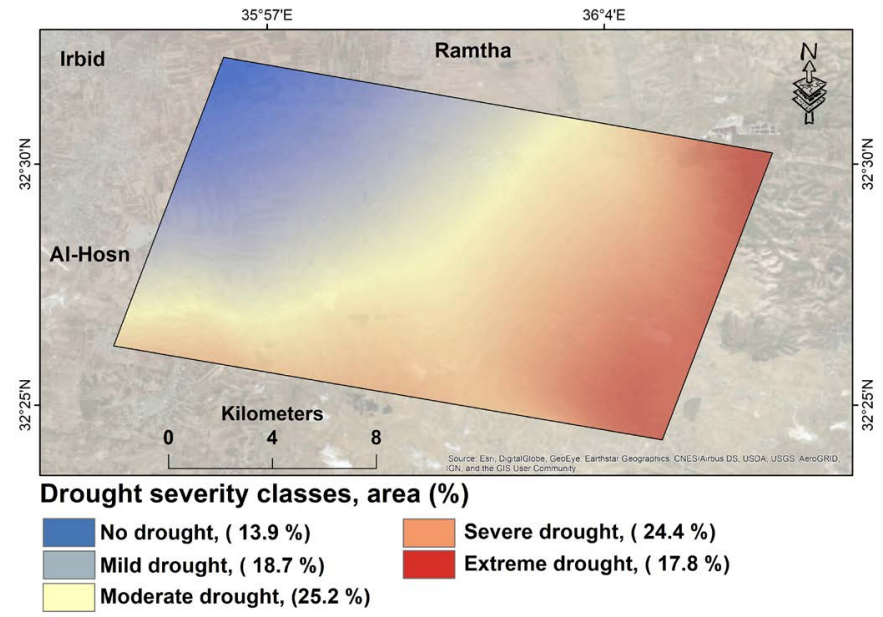

Figure 10. Drought severity map of the study area during March-2017.

Results of exploratory regression and OLS showed that no single factor could significantly explain all variations in spatial patterns of the drought severity map.

The use of two factors was better in explaining this map as PDI combined with $\mathrm{K}$ explained $59 \%$ of the map spatial pattern. The combination of remote 
Table 8. Summary of exploratory regression analysis and OLS for the map of drought severity in March.

\begin{tabular}{|c|c|c|c|c|}
\hline $\begin{array}{c}\text { Model } \\
\text { simplicity }\end{array}$ & Adj. $R^{2}$ & $J B$ & $V I F$ & Variable and model significance \\
\hline \multirow[t]{2}{*}{1} & 0.23 & 0.79 & 1 & $(-) \mathrm{K}_{0-10,}{ }^{*}$ \\
\hline & 0.59 & 0.75 & 1.15 & $(+)$ PDI, (-) $\mathrm{K}^{* *}$ \\
\hline \multirow[t]{3}{*}{2} & 0.51 & 0.84 & 1.05 & $(-) \mathrm{K},(-)$ Rainfall ${ }^{\star *}$ \\
\hline & 0.39 & 0.81 & 1.03 & (-) PVI, (-) Rainfall * \\
\hline & 0.58 & 0.69 & 1.99 & $(-)$ NDVI, (+) PDI, (-) K** \\
\hline \multirow[t]{2}{*}{3} & 0.57 & 0.68 & 2.02 & (+) PDI, (-) PVI, (-) $\mathrm{K}^{\star *}$ \\
\hline & 0.56 & 0.73 & 5.11 & $(-)$ MPDI, (-) NDVI, (+) PDI ${ }^{\star *}$ \\
\hline 4 & 0.61 & 0.68 & 6.29 & $(-)$ MPDI, (-) NDVI, (+) PDI, (-) K* \\
\hline 5 & 0.51 & 0.67 & 6.9 & (-) MPDI, (-) NDVI, (+) PDI, (+) PVI, (-) K \\
\hline
\end{tabular}

${ }^{\star} p=0.10$ (not significant), ${ }^{* *} p=0.05,{ }^{* *} p=0.01$. Where, Model fit. (Adj. $\left.R^{2}\right)$; Normality of Residuals $(J B)$; Collinearity $(V I F)$.

sensing drought indices of NDVI, PDI and MPDI could explain drought $56 \%\left(R^{2}\right.$ $=0.56)$ of variations in drought spatial pattern.

Adding $\mathrm{K}$ to these indices would increase the model redundancy as shown by the VIF values that increased when the four variables were used to explain the variations in drought severity map, as the VIF value reached 6.9 which became close to 7.5; the level at which model redundancy would start [23]. These results could indicate that $\mathrm{K}$ or remote sensing indices highly correlated $\mathrm{K}$ should form the basis for monitoring drought and mapping its severity.

\section{Conclusion}

Results showed that remote sensing indices showed different responses to soil moisture stress $(\mathrm{K})$ with similarities in trends of correlations, which were positive for MPDI and PDI and negative for NDVI and PVI. The correlations were significant with relatively high values of $R^{2}$ for the MPDI, NDVI, PVI and K during March-April when the vegetation cover of barley reached its maximum, indicating the possibility of using remote sensing indices for drought monitoring during this period. The correlations with remote sensing indices and $\mathrm{K}$ were also variable among the indices and for the different soil depths for which $\mathrm{K}$ was derived. This indicated the nature of each index and its response to either vegetation conditions or soil moisture conditions or both. Therefore, the combination of remote sensing in mapping drought severity would produce a map that could reflect soil moisture and vegetation. Results from the spatial statistics analysis for the drought severity map of March showed that the combination of PDI and $\mathrm{K}$ explained $59 \%$ of the variations in the spatial pattern of this map. The combination of remote sensing indices of PDI, MPDI and NDVI significantly explained $56 \%$ in the variations in the spatial pattern of this map. Therefore, the study recommends the use of these indices, particularly MPDI and PDI, to map and 
monitor drought at the scale of OLI and MSI data.

\section{Data Availability}

Some or all data, models, or code generated or used during the study are proprietary or confidential in nature and may only be provided with restrictions (e.g. maps and climatic data).

\section{Acknowledgements}

The authors acknowledge Ministry of Water and Irrigation (MWI) and the Ministry of Agriculture (MOA) for supplying some of the data used in this research. Acknowledgment is also extended for the Open Journal of Geology for cooperation and inputs from anonymous reviewers.

\section{Conflicts of Interest}

The authors declare no conflicts of interest regarding the publication of this paper.

\section{References}

[1] UNISDR (2009) Drought Risk Reduction Framework and Practices: Contributing to the Implementation of the Hyogo Framework for Action. United Nations Secretariat of the International Strategy for Disaster Reduction, in Partnership with the National Drought Mitigation Center, Geneva, 3-8.

[2] Dirmeyer, P.A., Guo, Z.C. and Gao, X. (2004) Comparison, Validation, and Transferability of Eight Multiyear Global Soil Wetness Products. Hydrometeor, 5, 1011-1033. https://doi.org/10.1175/JHM-388.1

[3] Meng, L. and Quiring, S.M. (2008) A Comparison of Soil Moisture Models Using Soil Climate Analysis Network Observations. Hydrometeor, 9, 641-659. https://doi.org/10.1175/2008JHM916.1

[4] Quiring, S. (2015) Hydrology, Floods and Drought. Reference Module in Earth Systems and Environmental Sciences, Encyclopedia of Atmospheric Sciences (Second Edition), Texas A\&M University, College Station, TX, USA, 193-200. https://doi.org/10.1016/B978-0-12-382225-3.00037-2

[5] USGS (2019) United States Geological Survey. https://glovis.usgs.gov/app

[6] Al-Bakri, J.T. and Suleiman, A. (2004) NDVI Response to Rainfall in Different Ecological Zones in Jordan. International Journal of Remote Sensing, 25, 3897-3912. https://doi.org/10.1080/01431160310001654428

[7] Ghulam, A., Qin, Q. and Zhan, Z. (2007) Designing of the Perpendicular Drought Index. Environmental Geology, 52, 1045-1052. https://doi.org/10.1007/s00254-006-0544-2

[8] Ghulam, A., Qin, Q., Teyip, T. and Li, Z.L. (2007) Modified Perpendicular Drought Index (MPDI): A Real Time Drought Monitoring Method. ISPRS Journal of Photogrammetry, 62, 150-164. https://doi.org/10.1016/j.isprsjprs.2007.03.002

[9] Al-Bakri, J.T., Salahat, M., Suleiman, A., Suifan, M., Hamdan, M.R., Khresat, S. and Kandakji, T. (2013) Impact of Climate and Land Use Changes on Water and Food Security in Jordan: Implications for Transcending "The Tragedy of the Commons". Sustainability, 5, 724-748. https://doi.org/10.3390/su5020724 
[10] Al-Bakri, J.T., Shawash, S., Ghanim, A. and Abdelkhaleq, R. (2016) Geospatial Techniques for Improved Water Management in Jordan. Water, 8, 132. https://doi.org/10.3390/w8040132

[11] MWI (2018) Jordan Water Sector-Rainfall for the Long-Term 1984-2017. Ministry of Water and Irrigation, Amman, 1-24.

[12] Al-Naber, G., Al-Bakri, J. and Saba, M. (2009) Monitoring Drought and Desertification in Jordan with Remote Sensing. Proceedings of the Remote Sensing and GIS Applications Symposium, Amman, Jordan, 20 April 2009, 53-61.

[13] Saba, M. (2015) Drought Analysis Using MODIS NDVI 250 m Time Series for Mafraq Area-Season 2013/2014. A Report for Regional Cooperation on Improved Water Resources Management and Capacity Building Program-Ministry of Water and Irrigation, NCARE, Baqa'a.

[14] Al-Bakri, J.T., Al-Khreisat, A., Shawash, S., Qaryouti, E. and Saba, M. (2017) Assessment of Remote Sensing Indices for Drought Monitoring in Jordan. Asian Journal of Geoinformatics, 17, 1-13.

[15] Al-Bakri, J.T., Brown, L., Gedalof, Z., Berg, A., Nickling, W., Khresat, S., Salahat, M. and Saoub, H. (2016) Modelling Desertification Risk in the North West of Jordan Using Geospatial and Remote Sensing Techniques. Geomatics, Natural Hazards and Risk, 7, 531-549. https://doi.org/10.1080/19475705.2014.945102

[16] Farhan, I.A. and Al-Bakri, J.T. (2012) Use of GIS and Remote Sensing to Assess Soil Erosion in an Arid to Semiarid Basin in Jordan. Proceedings of the International Conference on Sediment Transport. Modeling in Hydrological Watersheds and Rivers, Vol. 5, 145-152.

[17] Mandanici, E. and Bitelli, G. (2016) Preliminary Comparison of Sentinel-2 and Landsat 8 Imagery for a Combined Use. Remote Sensing, 8, 1014. https://doi.org/10.3390/rs8121014

[18] Casanova, D., Epema, G.F. and Goudriaan, J. (1998) Monitoring Rice Reflectance at Field Level for Estimating Biomass and LAI. Field Crops Research, 55, 83-92. https://doi.org/10.1016/S0378-4290(97)00064-6

[19] Shahabfar, A., Ghulam, A. and Eitzinger, J. (2012) Drought Monitoring in Iran Using the Perpendicular Drought Indices. International Journal of Applied Earth $O b$ servation and Geoinformation, 18, 119-127. https://doi.org/10.1016/j.jag.2012.01.011

[20] Baret, F., Clevers, J.G.P.W. and Steven, M.D. (1995) The Robustness of Canopy Gap Fraction Estimations from Red and Near-Infrared Reflectances: A Comparison of Approaches. Remote Sensing of Environment, 54, 141-151. https://doi.org/10.1016/0034-4257(95)00136-O

[21] Zhang, L., Jiao, W., Zhang, H., Huang, C. and Tong, Q. (2017) Studying Drought Phenomena in the Continental United States in 2011 and 2012 Using Various Drought Indices. Remote Sensing of Environment, 190, 96-106. https://doi.org/10.1016/j.rse.2016.12.010

[22] Mitchell, A. (2005) The ESRI Guide to GIS Analysis, Volume 2. ESRI Press, Redlands.

[23] Burnham, K.P. and Anderson, D.R. (2002) Model Selection and Multimodel Inference: A Practical Information-Theoretic Approach. 2nd Edition, Springer, New York.

[24] Xue, J. and Su, B. (2017) Significant Remote Sensing Vegetation Indices: A Review of Developments and Applications. Journal of Sensors, 2017, Article ID: 1353691. https://doi.org/10.1155/2017/1353691 
[25] Al-Bakri, J.T. and Taylor, J.C. (2003) Application of NOAA-AVHRR for Monitoring Vegetation Conditions and Biomass in Jordan. Journal of Arid Environments, 54, 579-593. https://doi.org/10.1006/jare.2002.1081

[26] Zargar, A., Sadiq, R., Naser, B. and Khan, F.I. (2011) A Review of Drought Indices. Environmental Reviews, 19, 333-349. https://doi.org/10.1139/a11-013

[27] Zhe, L. and Debao, T. (2014) A Modified Perpendicular Drought Index in NIR-Red Reflectance Space. IOP Conference Series. Earth and Environmental Science, 17, Article ID: 012040. https://doi.org/10.1088/1755-1315/17/1/012040 